\title{
Chemistry Cube Game - Exploring Basic Principles of Chemistry by Turning Cubes
}

\author{
Markus T. Müller*
}

\begin{abstract}
The Chemistry Cube Game invites students at secondary school level 1 and 2 to explore basic concepts of chemistry in a playful way, either as individuals or in teams. It consists of 15 different cubes, 9 cubes for different acids, their corresponding bases and precursors, and 6 cubes for different reducing and oxidising agents. The cubes can be rotated in those directions indicated. Each 'allowed' vertical or horizontal rotation of $90^{\circ}$ stands for a chemical reaction or a physical transition. Two different games and playing modes are presented here: First, redox chemistry is introduced for the formation of salts from elementary metals and non-metals. Second, the speciation of acids and bases at different $\mathrm{pH}$-values is shown. The cubes can be also used for games about environmental chemistry such as the carbon and sulphur cycle, covering the topic of acid rain, or the nitrogen cycle including ammoniac synthesis, nitrification and de-nitrification.
\end{abstract}

Keywords: Acids/bases · Basic chemical principles · Chemistry Cube Game · Collaborative/cooperative learning · Equilibrium · Inquiry-based/discovery learning · Humor/puzzles/games · Oxidation/reduction · Salt formation $\cdot$ Secondary school level 1 and $2 \cdot$ Speciation

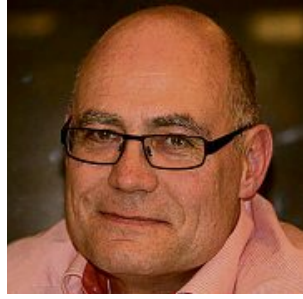

\section{Introduction}

Games with different cubes or dices for chemistry courses have been presented before. Chem-Cubes ${ }^{\mathrm{TM}}$ was developed by Science Kit \& Boreal Laboratories. It contains 12 different small hardwood cubes, offers different games for ions and elements and can be bought at Ward's Science. ${ }^{[1]}$ In 2016 Harno and Gorges published a manual to print, cut and handicraft cubes with different ions mainly to exercise and learn salt names. ${ }^{[2]}$

The chemistry cubes presented here (Fig. 1) focus on the speciation of acids and bases, of elementary metals $\left(\mathrm{Me}^{\circ}\right)$ and the corresponding metal-cations $\left(\mathrm{Me}^{\mathrm{x}+}\right)$ as well as of non-metals $\left(\mathrm{O}_{2}^{\circ}\right)$ and their anions $\left(\mathrm{O}^{2-}\right)$. In addition, the origin of the substances, phase transitions and solubility equilibria of gases in water have been considered and are shown on the cubes in a way that the different turning options, that are possible, chemically make sense.

Different chapters of the chemistry curriculum on salts, chemical equilibrium, acid and bases as well as redox chemistry, but also different topics of environmental chemistry can be experienced by playing with the cubes. The basics of salt formation, salt formulae and their ion notation, solvation, solubility and crystallization, can be worked out. Another focus lays in the acid and base species that are present at different $\mathrm{pH}$-values. The aspect of $\mathrm{pH}$ and $\mathrm{p} K$-values can be easily experienced, as well as the titration of an acid or a base.

The games in redox chemistry start with the formation of salts from different elementary metals and non-metals. Using oxidation numbers, redox reactions can be recognized and half cell reactions can be written down for future corrections and discussion.

Environmental chemistry starts with the carbon cycle and the different equilibria that have to be considered. Acidic rain is treated using the examples of sulfuric and nitric acid. Here we follow the goal to demonstrate complex connections between different reactions and to discover their dependence on ambient conditions, such as $\mathrm{pH}$-value, temperature, pressure. The nitrogen cycle, where aerobic and anaerobic conditions play a major role, combines the different aspects and themes treated before.
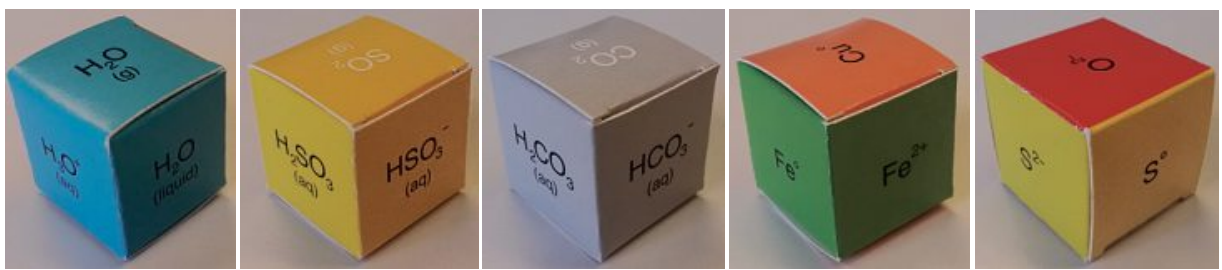

Fig. 1. Examples of five different cubes of the chemistry cube game (for the design see also Figs 2 to 5$)$. 


\section{Design of the Cubes and Role of the Players}

The cubes are designed in different colors (Fig. 2 - Fig. 5). Change in font color while turning a cube stands for a chemical reaction (Fig. 3). A slight change in background color stands for an electron transfer (Fig. 4 and Fig. 5) also visible in the change of the charge of the species. The zero charge of the neutral species such as $\mathrm{Fe}^{\circ}, \mathrm{Cu}^{\circ}, \mathrm{N}_{2}^{\circ}$ or $\mathrm{O}_{2}^{\circ}$ is also shown.

Generally, gaseous species (g) are on the top of the cube, aqueous species on the sides (aq) and solid species (s) as well as additional information on the bottom of the cubes (e.g. carbon cube, sulfur cubes).

\section{Acid and Base Cubes}

The different species of the acids and their corresponding bases are shown on the sides of the cubes (Fig. 3). The acidity constants, $\mathrm{p} K$-values, can be looked up on the bottom of the cubes, below the acid species. The idea is to look it up and memorize some of the values by playing. The acidity constants, $\mathrm{p} K$-values, used on the cubes were taken from ref. [3].

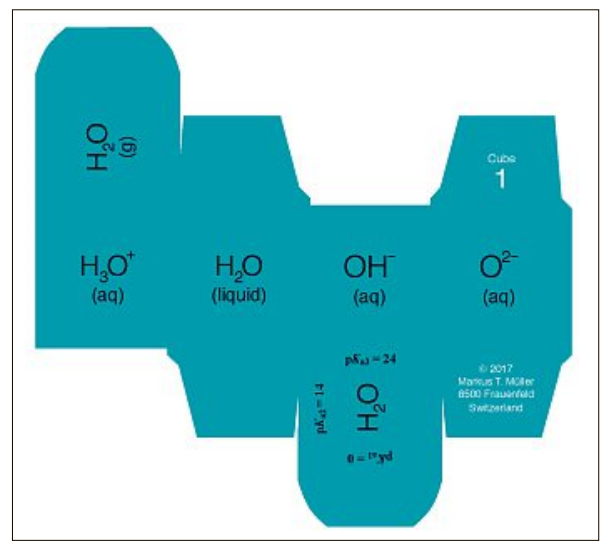

Fig. 2. Cube 1 with $\mathrm{H}_{2} \mathrm{O}$ species.

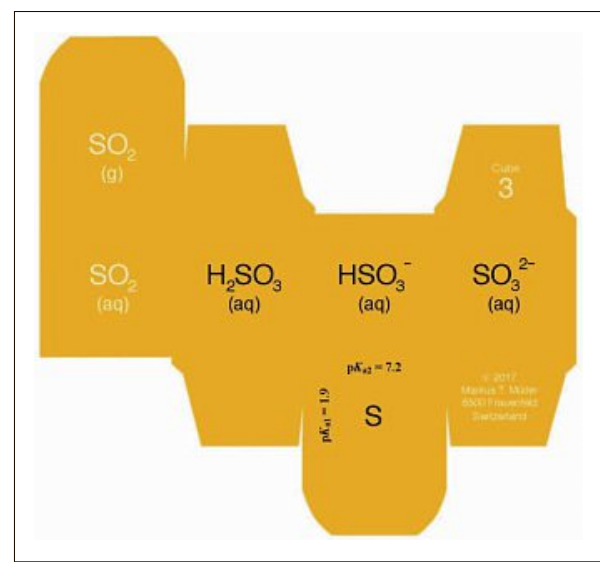

Fig. 3. Cube 3 with $\mathrm{H}_{2} \mathrm{SO}_{3}$ species and precursors.

\section{Metals, Non-Metals and their lons}

The cubes for metals, non-metals and their ions (Fig. 4 and Fig. 5) can be used for redox chemistry or salt formation. If you turn a cube with an uncharged metal (e.g. magnesium: $\mathrm{Mg}^{\circ}$ ) to the left, an oxidation step (electron donation) occurs and the magnesium cation $\left(\mathrm{Mg}^{2+}\right)$ is formed. If you turn a cube with an uncharged non-metal (e.g. oxygen: $\mathrm{O}_{2}^{\circ}$ ) to the right, a reduction step (electron uptake) occurs and the oxygen anion $\left(\mathrm{O}^{2-}\right)$ is formed.

\section{Salts and their Ion Notation}

All the cubes can be used to derive salt formulae and to learn salt names. We follow the concept to use, besides the salt formula (e.g. $\mathrm{Na}_{2} \mathrm{CO}_{3}$ ), also the ion notation of the salt $\left(2 \mathrm{Na}^{+}+\mathrm{CO}_{3}{ }^{2-}\right)$, that can be expressed by the cubes. Salt names can be derived easily using a list with the names of the ions.

For students it is always a challenge to distinguish between the uncharged elementary substance $\left(\mathrm{Mg}^{\circ}, \mathrm{Al}^{\circ}, \mathrm{O}_{2}^{\circ}, \mathrm{Cl}_{2}^{\circ}\right.$, $\left.\mathrm{S}^{\circ}\right)$, their ions $\left(\mathrm{Mg}^{2+}, \mathrm{Al}^{3+}, \mathrm{O}^{2-}, \mathrm{Cl}^{-}, \mathrm{S}^{2-}\right)$ and the formulae of the corresponding products

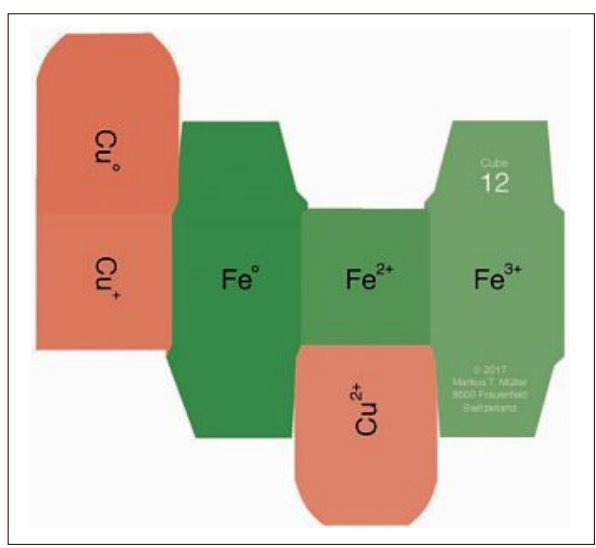

Fig. 4. Cube 12 with metal species (cations).

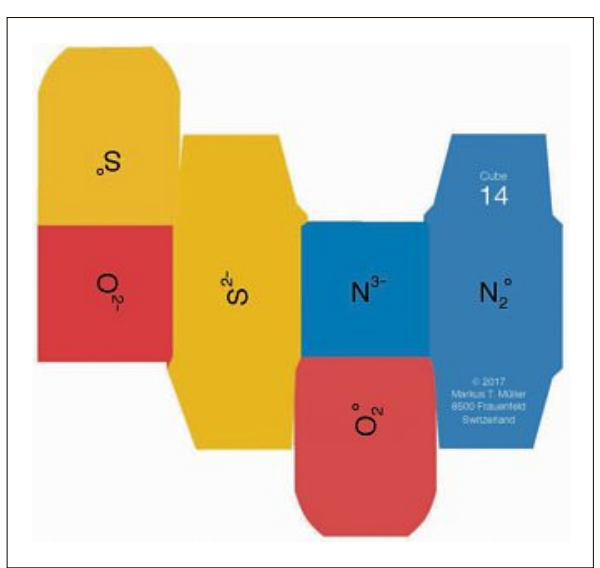

Fig. 5. Cube 14 with non-metal species (anions).
$\left(\mathrm{MgO}, \mathrm{MgCl}_{2}, \mathrm{Al}_{2} \mathrm{O}_{3}, \ldots\right)$ formed in salt formation reactions. Using the chemistry cubes they train and learn the differentiation between these species easily.

\section{Role of the Teacher}

The cubes allow the students to learn by playing either by following the game instructions (handouts) or after a short introduction given by the teacher. The teacher can act as a game leader, moderator, questioner or as performer of a corresponding experiment.

The teacher can also decide in which form the students have to write down results in predefined tables or documentation forms. You will find suggestions and tips in the two examples shown in the next section or in the instructions of the other Chemistry Cube Games.[4]

\section{Role of the Students}

Students can play alone, in groups or as a class. The learning experience can be enhanced by taking notes and by discussing the results in the team. The games give them the opportunity to play various topics and learn and understand chemistry in a different way. If teachers set up competitions, as suggested for some games, then students will find strategies to win.

\section{Examples of Chemistry Cube Games}

The goal of the first example game 'salt formation and redox reactions' (game 3.1, Fig. 6) is to introduce redox reactions by salt formation from elementary substances. On the cubes, the students see the different charges of metals and non-metals and can combine different ions to salts expressed in ion notation. The advantage of this notation is that it helps students to identify salts and their ions.

The goal of the second example game 'acid and base species at different $\mathrm{pH}$ values' (game 2.1, Fig. 7) is that students can identify the main species of an acid or a base present in aqueous solutions at different $\mathrm{pH}$ values. The game can be introduced either using the law of mass action, the Henderson-Hasselbach-equation (see game 2.2), ${ }^{[4]}$ the equilibrium concept of Le Chatelier (Eqns (1) and (2) in Fig. 8) or just by explaining the meaning of the $\mathrm{p} K_{\mathrm{a}}$-value as shown here in game 2.1.

We decided to print $\mathrm{p} K$-values for the different water species as well, but we recommend not to use the water cubes in this game as we focus on the acids and bases in an aqueous solution. The role of the 


\section{Example 1: Salt Formation - Redox Reactions (Game 3.1)}

\begin{tabular}{|l|l|l|l|l|l|l|l|l|l|}
\hline 4 & 5 & 6 & 7 & & 9 & 10 & 11 & 12 & Univ. \\
class level recommendation
\end{tabular}

\section{Metals react with non-metals to form salts by means of electron transfer}

The goal of this game is to introduce redox reactions:

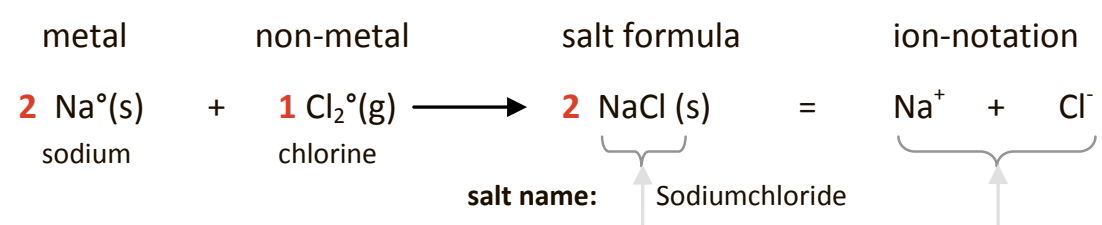

Two uncharged elementary substances react to an ionic compound. The salt formula is shown in the ion-notation, which can be expressed with the cubes. It also shows that electrons have been transferred in this reaction. The partial reactions the student will have to express on the reporting sheet are:

\section{Oxidation:}

$\mathrm{Na}^{\circ}$

$\longrightarrow \mathrm{Na}^{+}+1 \mathrm{e}^{-}$

$\mathrm{e}^{-}$balance

(e- donation)

Reduction:

$\mathrm{Cl}_{2}^{\circ}+2 \mathrm{e}^{-} \longrightarrow 2 \mathrm{Cl}^{-}$

$\times 2$

(e- uptake)

\section{Game setup:}

Game for 2 students, 2 sets of cubes, and reporting sheet for correction and scoring .

$1^{\text {st }}$ player ("challenger"): Selects a metal and a non-metal cube.

$2^{\text {nd }}$ player ("challengee"): Combines the resulting ionic compound (ion-notation). Points are given by the challenger for the correct salt-formula (1), the correct name of the salt (1), the stoichiometrically correct reaction with the salt formula and its ion-notation (A) (1). Note also the part reactions of the oxidation (B) (1) and the reduction (C) (1), including the electron balance.

$1^{\text {st }}$ player: Give points for each correct step (max 5 points). (change roles and play again)

$\begin{aligned} & \text { metal }+ \text { non-metal } \longrightarrow \text { salt formula } \\ & \text { salt name }\end{aligned}$
Oxidation:
Reduction:

Cubes required for this game:
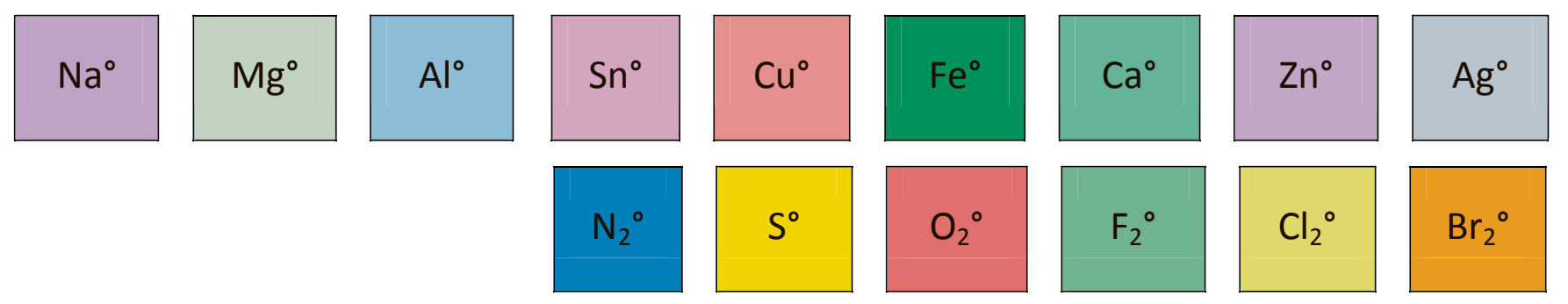

$\mathrm{Br}_{2}^{\circ}$ 


\section{Example 2: Acids and Bases (Game 2.1)}

\begin{tabular}{l|l|l|l|l|l|l|l|l|l|}
4 & 5 & 6 & 7 & 8 & & & 11 & 12 & Univ. \\
class level recommendation
\end{tabular}

\section{Which acid and base species occur at different pH-values?}

The goal of this game is that students can decide which acid and base species occur in aqueous solutions at different $\mathrm{pH}$ values.

Preparation:

Place the different acid and base cubes (see below) on a table with 4-6 students. The students have to place and turn all cubes such that the fully protonated form lies side up on the table $\left(\mathrm{H}_{2} \mathrm{CO}_{3}\right.$, $\mathrm{H}_{2} \mathrm{SO}_{3}, \mathrm{H}_{2} \mathrm{SO}_{4}, \mathrm{H}_{2} \mathrm{~S}, \mathrm{NH}_{4}{ }^{+}, \mathrm{HNO}_{2}, \mathrm{HNO}_{3}, \mathrm{H}_{3} \mathrm{PO}_{4} \ldots$ ). The acidity constants ( $\mathrm{p} K_{\mathrm{a}}$-value) can be looked up turning the cube forward - at the bottom of the protonated species.

Playing rules:

If the $\mathrm{pH}$-value in an aqueous solution containing an acid (e.g. $\left.\mathrm{H}_{2} \mathrm{CO}_{3}\right)$ is lower than the $\mathrm{p} K_{\mathrm{a}}$-value $(\mathrm{pH}$ $\left.<\mathrm{p} K_{\mathrm{a} 1}=6.4\right)$, then the species facing up remains the main species. If the $\mathrm{pH}$-value is higher than the $\mathrm{p} K_{\mathrm{a} 1}$-value $\left(\mathrm{pH}>\mathrm{p} K_{\mathrm{a} 1}=6.4\right)$ of acid 1 , you will have to turn this cube to the left and acid $1\left(\mathrm{H}_{2} \mathrm{CO}_{3}\right)$ has been deprotonated to base $1\left(\mathrm{HCO}_{3}{ }^{-}\right)$.

The cubes will be turned from acid 1 to its corresponding base 1 if the $\mathrm{pH}$-value is higher than $\mathrm{p} K_{\mathrm{a} 1}$. If base $1\left(\mathrm{HCO}_{3}{ }^{-}\right)$can act as acid 2, the cubes can be turned further to base 2 , if the $\mathrm{pH}$ is higher than $\mathrm{p} K_{\mathrm{a} 2}$ (see equation (1)).

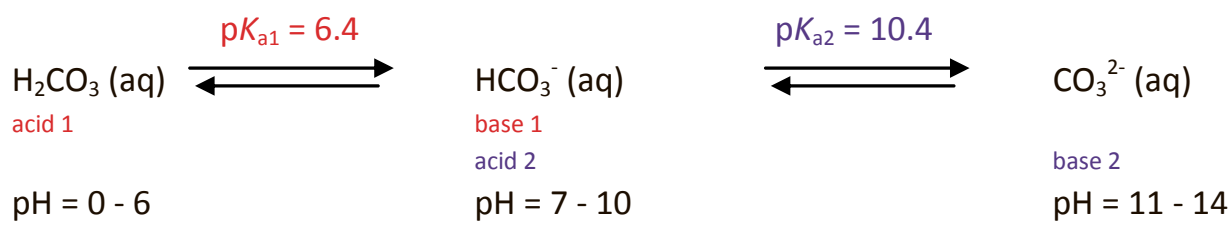

Game: $\quad$ Start with an acidic solution with $\mathrm{pH}=0$.

$\mathbf{p H}=\mathbf{0} \quad$ Decide which species of the 8 different acids are predominant at $\mathrm{pH}=0$. Face them up.

$\mathbf{p H}=1 \quad 1^{\text {st }}$ student Decide for the 8 cubes what happens when $\mathrm{pH}=1$. Turn cubes if necessary.

$\mathbf{p H}=\mathbf{2} \quad 2^{\text {nd }}$ student: Decide for the next 8 cubes what happens when $\mathrm{pH}=2$. Turn cubes.

pH = $3 \quad 3^{\text {rd }}$ student: Increase $\mathrm{pH}$-value by increments of 1 and turn the appropriate cubes.

All players note the results in a pre-prepared table as the one shown below.

$\mathbf{p H}=\ldots . \quad$ Increase $\mathrm{pH}$-value again by increments of 1 and turn the appropriate cubes. Note species.

pH = 14 In which form (species) occur the different acids and bases at $\mathrm{pH}=14$ ?

Combine the results of the groups and build as a class the species for $\mathrm{pH}=1$ to 12 (or 0 to 14 ).

\begin{tabular}{|l|c|c|c|c|c|c|c|c|c|}
\hline student & $\mathrm{pH}$ & $\mathrm{H}_{2} \mathrm{CO}_{3}$ & $\mathrm{H}_{2} \mathrm{SO}_{3}$ & $\mathrm{H}_{2} \mathrm{SO}_{4}$ & $\mathrm{H}_{2} \mathrm{~S}$ & $\mathrm{NH}_{4}^{+}$ & $\mathrm{HNO}_{2}$ & $\mathrm{HNO}_{3}$ & $\mathrm{H}_{3} \mathrm{PO}_{4}$ \\
\hline all & 0 & & & & & & & & \\
\hline $1^{\text {st }}$ & 1 & & & & & & & & \\
\hline $2^{\text {nd }}$ & 2 & & & & & & & & \\
\hline $3^{\text {rd }}$ & 3 & & & & & & & & \\
\hline & etc & & & & & & & & \\
\hline
\end{tabular}

1 cube of each per 1 or 2 students

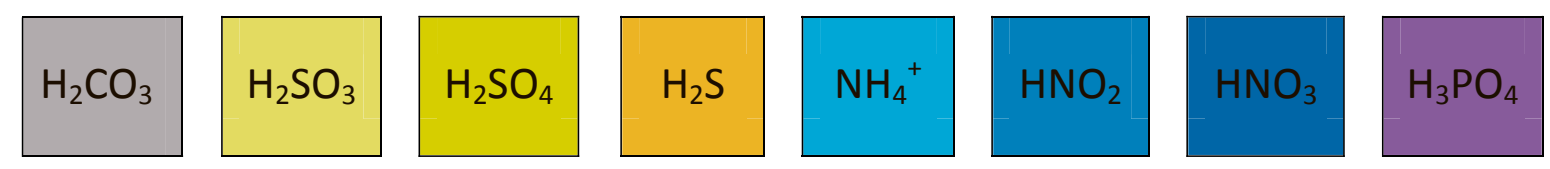




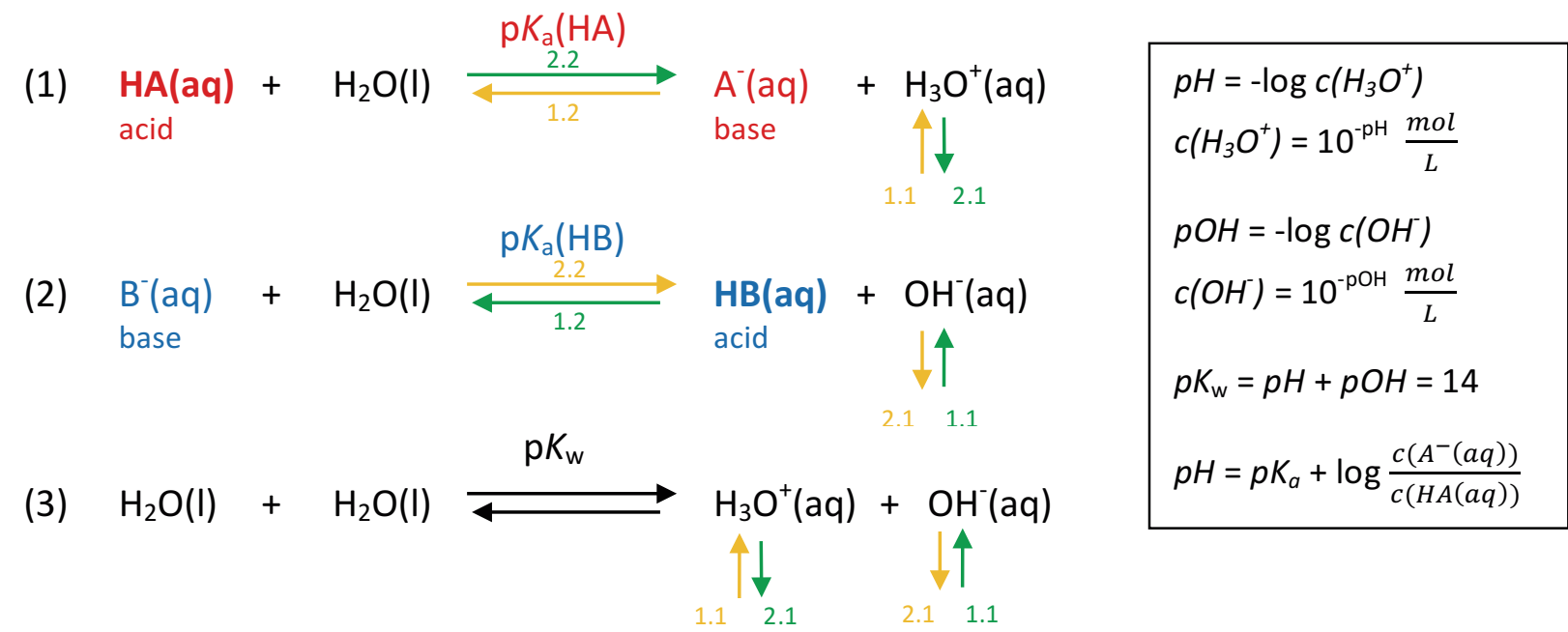

\begin{tabular}{|c|c|c|c|}
\hline $\mathrm{c}\left(\mathrm{H}_{3} \mathrm{O}^{+}\right)$ & $\mathrm{c}\left(\mathrm{OH}^{-}\right)$ & Sequence of the disturbance of the equilibrium (Le Chatelier) & pH \\
\hline 4 & $\downarrow$ & $\begin{array}{l}\text { The addition of a strong acid leads to an increase of the concentration of } \\
\mathrm{c}\left(\mathrm{H}_{3} \mathrm{O}^{+}\right)(1.1) \text { and also to a decrease of the concentration of } \mathrm{c}\left(\mathrm{OH}^{-}\right)(2.1) \text { and } \\
\text { shifts the equilibrium in both equations (1) and (2) towards the acid species } \\
(1.2,2.2) \text {. }\end{array}$ & $\nabla$ \\
\hline$\nabla$ & $\uparrow$ & $\begin{array}{l}\text { The addition of a strong base leads to an increase of the concentration of } \\
\mathrm{c}\left(\mathrm{OH}^{-}\right)(1.1) \text { and to a decrease of the concentration of } \mathrm{c}\left(\mathrm{H}_{3} \mathrm{O}^{+}\right)(2.1) \text { and } \\
\text { shifts the equilibrium towards the base species }(1.2,2.2) \text {. }\end{array}$ & 广 \\
\hline
\end{tabular}

Fig. 8. Acid and base species at different $\mathrm{pH}$ values.

solvent and the thermodynamic aspects as well as activities and activity coefficients are usually neglected at secondary school level 2.

\section{Discussion and Conclusions}

For students, the distinction between elements and ions is difficult. Typically, half of the students are able to write down a correct reaction equation to form a salt out of the elements, e.g. a metal and a nonmetal. The cubes, on which the neutral and the ionic species are all present, help to improve this learning step. The experience is, that the game 'salt formation and redox reactions' (Fig. 6) is helpful particularly for the weaker students to understand and learn the difference between elements and their ions.

In another game about the solubility of salts (game 1.2), ${ }^{[4]}$ the students have to make a decision, set up a hypothesis and find out rules about "which salts (or ions) are better soluble than others". The combination of interaction and decision-making with the cubes on the table and the investigation of the solubility in the worldwide web using a tablet computer or a smart phone, makes this game more appealing for the students. For some of them, the points they could win were less important than the challenge to try to understand how it works. They also tried to check solubility for other salts (e.g. potassium salts), that cannot be expressed by the game.

The students learn in the second example (game 2.1, Fig. 7), that the species in which an acid or a base occurs depends on the $\mathrm{pH}$ value of the solution. As these different species are present on the same cube, they view the compound in its protonated and deprotonated form. They also realize that the molecular ions such as sulfate or phosphate belong to the families of the sulfuric or phosphoric acid, respectively (Fig. 9).

With the $\mathrm{p} K$-value printed on the bottom of the cubes, the students look them up, because they need them for their decision, and memorize them while playing the game. Another major learning step for the students was that the different acids are deprotonated at different $\mathrm{pH}$-values and that the stronger acids, such as sulfuric and nitric acid, can hardly be found in their fully protonated form at $\mathrm{pH}>0$.

In game 2.2[4] the buffer effect of an acid and base pair at $\mathrm{pH}$-values close to the $\mathrm{p} K$-values can be discovered. The students find that at a $\mathrm{pH}$-range of $\mathrm{pH}=\mathrm{p} K_{\mathrm{a}} \pm 1$ the acids are deprotonated or the bases are protonated, that means that an acid-base- reaction takes place and they have to turn a lot of cubes.

When we look at the games 1.2 and 1.3 about the solubility of salts (not presented here), ${ }^{[4]}$ then the chemistry cubes offer the opportunity to discuss the role of the $\mathrm{pH}$-value for the solubility of salts such as carbonates, sulfates, oxides and sulfides and how a change of the $\mathrm{pH}$ value of the solution can help to dissolve or precipitate a hardly soluble salt.

The acid and base cubes are also used for different games about environmental chemistry (games 4.1-4.4). ${ }^{[4]}$ The carbon, sulfur and nitrogen cycles with different phase transition equilibriums and redox reactions can be discovered. The students found the cubes helpful not only for a better understanding of the single steps of the different chemical reactions but also of the bigger context. Besides this it is also an advantage that they only see the formulae and when they have to explain each other what happens in these steps, they have to use the names of the compounds and ions. As my students are not really keen on learning formulae by heart, it was easier for them to learn the names by using them in a given and attractive context.

The chemistry cubes allow many different playing forms. The input of the teacher before the start of the game is important. 
Fig. 9. Result of a class for the speciation of different acids and bases at different $\mathrm{pH}$-values.

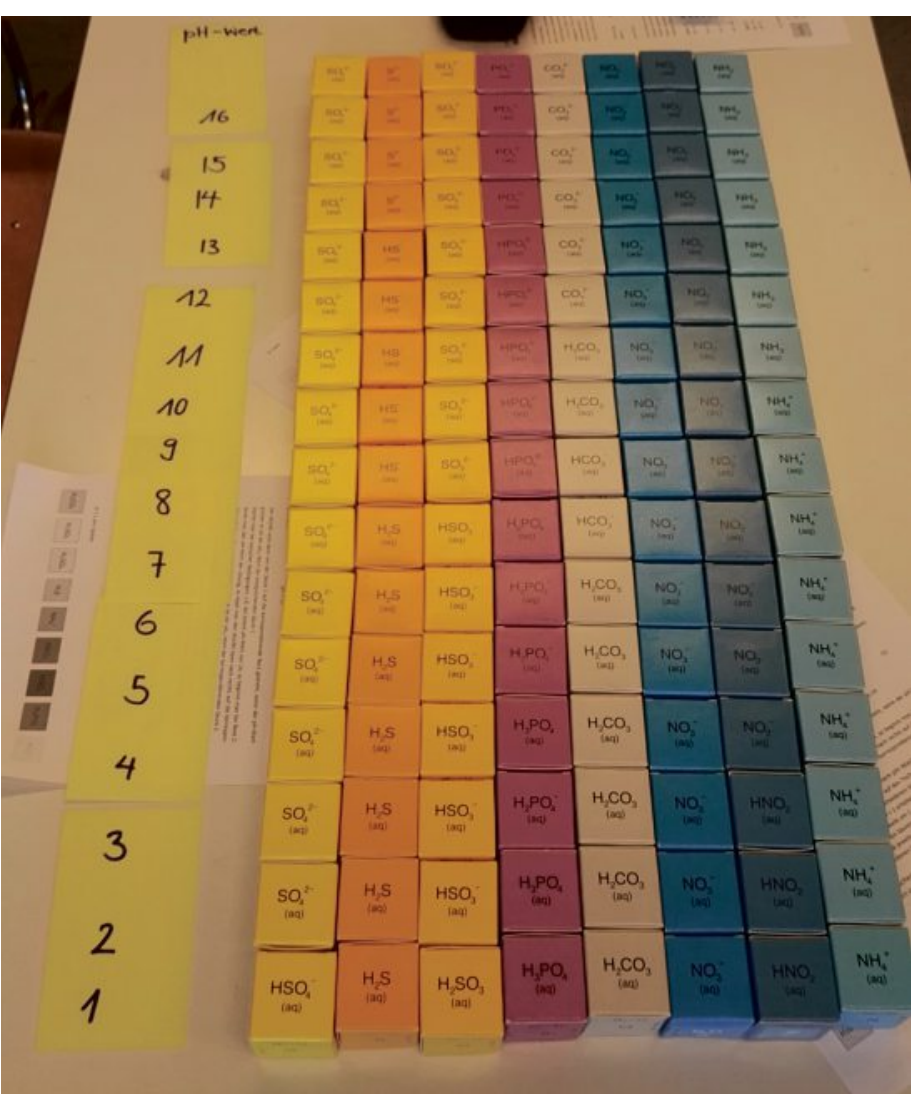

The teacher has to decide what goal the students should achieve in the game and in which form the results are written down and summarized. After that, the role of the teacher turns into a spectator, a moderator or a questioner who accompanies the playing groups. When students start playing in teams, they explain one another how it works, what they think. They learn from and teach one another. If this happens in

\section{Distribution and Game Instructions}

The Chemistry Cube Game can be ordered directly at the vsn-shop (www.vsnshop.ch). A free sample box is offered by the Swiss Chemical Society (SCS) and can be requested directly from the author. The game instructions and further information are available in German, English and French on our homepage (www.swisschemcube.ch).

\section{Acknowledgments}

I would like to thank my colleagues Hansueli Ehrensperger, Jörg Engweiler, Vesna Klingel and my classes at Kantonsschule Frauenfeld (for feedback), Peter Schaltegger (graphics), Hansruedi Dütsch (distribution), Nadine Blanchard (French translation), Uwe Schmitz and his company ChemCube $\mathrm{GmbH}$ (Spanish translation). I would also like to thank the Swiss Chemical Society (SCS) and the SCNAT for the financial support.

Received: October 15, 2017

[1] Ward's Science: https://www.wardsci.com/ store/product/8869600/chem-cubes accessed 26.11.2017.

[2] M. Harno, M. Gorges, 'Die geladenen Würfel', Praxis der Naturwissenschaften Chemie im Unterricht 2016, 4, 65.

[3] 'Formeln, Tabellen, Begriffe', 5. Auflage, 2015, Editors: DMK, DPK, DCK, Orell Füssli Verlag.

[4] www.swisschemcube.ch/english/game-instructions/accessed 12.12.2017. 